\title{
THESES
}

\section{IMMUNE SYSTEM ACTIVATION PARAMETERS IN THE NERVOUS SYSTEM INFLAMMATORY RESPONSE OF PATIENTS WITH NEUROMYELITIS OPTICA DIAGNOSIS (ABSTRACT)*. THESIS. RIO DE JANEIRO, 2007.}

\author{
MARIA LÚCIA VELLUTINI PIMENTEL **
}

Neuromyelitis optica (NMO) is an inflammatory, demyelinating disease of the central nervous system (CNS) characterized by the association of a serious acute or subacute myelitis and unilateral or bilateral optic neuritis. NMO patients usually have a worse clinical presentation and more deficits after each bout, being distinct from patients with multiple sclerosis (MS) by the symptomatic stereotypy, although fulfilling the McDonald's criteria for MS. Neuropathologic studies demonstrated an association among demyelinating lesions in NMO and peri-vascular deposits of immunoglobulin, local activation of complement cascade and eosinophilic infiltration. Humoral markers would be therefore implicated in the pathogenesis of NMO.

The present study aimed to analyze the immunological parameters of NMO patients from the out-patient unit of demyelinating diseases at Hospital Universitário Clementino Fraga Filho, Rio de Janeiro Federal University (HUCFF-UFRJ) and Santa Casa da Misericórdia do Rio de Janeiro (SCMRJ), Brazil.

NMO diagnosis was established based on Wingerchuck et al. (1999) criteria. Production of IgG and IgA antibodies to antigens of myelin basic protein (MBP), proteolipid (PLP) 95-116, myelin oligodendrocyte glycoprotein (MOG) 92-106, and the cytokines interleukin-4 (IL-4) and interferon- $\gamma$ (INF- $\gamma$ ) were assessed by Elisa assay.

The cohort was formed by twenty-eighth NMO patients, twenty-one females, seven males age ranged from 25 to 62 years old. A control group was formed by twenty-six healthy patients, fifteen females, eleven males age ranged from 18 to 43 years old. NMO patients had significant high levels of reactive immunoglobulins of isotypes IgG to MOG 92-106 ( $p<0.0001)$, PLP 95-116 $(p=0.0002)$ and MBP $(p<0.0001)$, and solely IgA to MBP $(p<0.0001)$. Increased production of IL$4(p=0.0084)$ indicates an important role for this cytokine in the activation of Th2 regulatory cells and of the IgA producers B lymphocyte. However, INF- $\gamma$ $(p=0.61)$ levels were similar to healthy controls.

Our results indicate that activation of humoral immunity with increased production of reactive immunoglobulins for some encephalitogenic myelin antigens play an important role in the pathophysiology of NMO.

KEY WORDS: neuromyelitis optica, pathophsiology, immunology.

*Estudo de parâmetros de ativação do sistema imune na neuro-inflamação em pacientes com diagnóstico clínico de Neuromielite Óptica (Resumo). Tese de Doutorado. Programa de Pós-Graduação em Clínica Médica Faculdade de Medicina, Universidade Federal do Rio de Janeiro (Área: Neurologia). Orientadores: Soniza Vieira Alves-Leon e Ângelo Maiolino.

**Address: Rua Custódio Serrão 36 / 1001, 22470-230 Rio de Janeiro RJ, Brasil (mlvpimentel@terra.com.br).

\section{STRUCTURAL CHANGES OF THE TEMPORAL POLE IN HIPPOCAMPAL SCLEROSIS: STUDY BASED ON THE FLAIR SEQUENCE AND ON VOLUMETRY BY MAGNETIC RESONANCE (ABSTRACT)*. THESIS. SÃO PAULO, 2007.}

\section{HENRIQUE CARRETE JR**}

Purpose: To examine temporal pole (TP) signal and quantitative changes in temporal lobe epilepsy (TLE) patients with hippocampal sclerosis (HS) using coronal fluid-attenuated inversion-recovery (FLAIR) and volumetric MRI sequences and investigate the relationship between these changes and clinical parameters.

Method: We studied 120 patients with TLE and uni or bilateral HS detected by MRI and 30 age and sex- matched healthy control subjects. Coronal FLAIR images of TP were independently assessed by visual analysis, focusing gray/white matter demarcation loss and classifying this temporal pole signal abnormality (TPA) according to regional involvement in anteromedial and/or lateral. We have also analyzed quantitatively the volumes of the TP from patients and controls.

Results: Sixty-one (51\%) of 120 patients had left 
HS, 46 (38\%) had right HS and 13 (11\%) had bilateral HS. TPA was not present in any of controls. Ninety (75\%) of 120 patients had associated TPA. TPA was always ipsilateral to unilateral HS and usually $(70 \%)$ ipsilateral to the more affected hippocampus in bilateral cases. The HS side made difference regarding the presence of TPA, with a left side preference. The anteromedial zone of TP was affected in $27(30 \%)$ out of 90 patients. In $63(70 \%)$ patients the lateral zone were also affected. The presence of TPA was significantly associated with a younger age at onset of habitual seizures, but not with history of febrile seizure (FS) or other initial precipitating injury (IPI) in childhood, duration of epilepsy and seizure frequency. In patients with TPA there was a trend toward younger age at IPI as compared with patients without it. Quantitative analysis of TP demonstrated significant atrophy in $42(35 \%)$ of 120 patients with HS. The TP volume was reduced meanly ipsilateral but also contralateral to HS in some cases. In patients with right HS, the mean volume of ipsilateral TP was $15 \%$ less than the mean volume of the corresponding lobe in controls, whereas in patients with left HS, the mean volume of ipsilateral TP was $13 \%$ less than the mean volume of the corresponding TP in controls. Patients with and without history of FS did not differed significantly in TP volume. The TP volume also failed to correlate with seizure frequency. The volume of TP was negatively correlated with duration of epilepsy, ipsilateral and contralateral to the HS. The degree of TP volume asymmetry index was not associated with the presence of TPA.

Conclusion: Three quarter of ELT patients with HS show TPA on coronal FLAIR images, always ipsilateral to $\mathrm{HS}$ in unilateral cases, with the anteromedial zone being affected in all. In bilateral HS, TPA is present ipsilateral to the more affected hippocampus in $70 \%$ of the cases. TPA occurring in $87 \%$ of left sided HS patients suggests a more widespread involvement when the dominant hemisphere is affected. There is an association between TPA and a younger age at seizure onset, whereas the patient age and the disease duration are negatively correlated with TP volume, ipsilateral and contralateral to HS.

KEY WORDS: hippocampal sclerosis, temporal lobe pole, MRI.

*Alterações estruturais do pólo temporal na esclerose hipocampal: estudo baseado na seqüência Flair e na volumetria por ressonância magnética (Resumo). Tese de Doutorado, Universidade Federal de São Paulo - Escola Paulista de Medicina. Orientador: Nitamar Abdala. Co-orientador: Jacob Szejnfeld.

** Address: DDI, EPM-UNIFESP, Rua Botucatu 740, 04023-900 São Paulo SP, Brasil (a/c Dr. Roberto Gomes Nogueira).

\section{POST-CRANIOTOMY HEADACHE AFTER SURGERY FOR TREATMENT OF CEREBRAL ANEURYSMS (ABSTRACT)*. THESIS. SÃO PAULO, 2006.}

\section{PEDRO AUGUSTO SAMPAIO ROCHA FILHO**}

Introduction: Post-craniotomy headache can cause a great repercussion on the quality of life of those who suffer it. However, literature on this subject lacks prospective studies on this condition. We studied the behavior and characteristics of the headache on the first six months after craniotomy.

Method: Patients with cerebral aneurysms were evaluated at the Clinics Hospital of the University of São Paulo Medical School, between 10/17/2002 and $10 / 02 / 2003$ in the pre-surgical period, and followed during six months after the surgery. We used semistructured interviews, headache diaries, Hospital Anxiety and Depression Scale, Epworth Sleepiness Scale, SF-36 and McGill Pain Questionnaire. Dentists evaluated the presence of temporomandibular disorder in the post-surgical period.

Results: 79 patients were included, with a mean age of 45.3 years, $64.6 \%$ were female, and 72 concluded the follow-up. 87 craniotomies were per- formed (pterional: $89.7 \%$; frontal: $4.6 \%$; orbitozygomatic: $5.8 \%$ ). Post-craniotomy headache was observed in $91.1 \%$, early in the post-surgical period (4 days), being significantly more precocious in those with headache caused by subarachnoid hemorrhage in the pre-surgical evaluation. There were changes in the headache diagnosis, side and sites, after surgery that did not change during the follow-up period. The frequency of the headache had an average increase of 14 days (median=1) on the first trimester of the pos-surgical period, compared to the trimester before surgery and continued at a rate of 6.9 days ( $m e d i a n=0)$ higher on the second trimester. There was an average decrease of 7.9 days (median=1) from the first to the last three months of follow-up. The presence of subarachnoid hemorrhage did not influence headache frequency. There was a positive relation between headache frequency and depressive and anxiety symptoms. The headache on the second trimester 